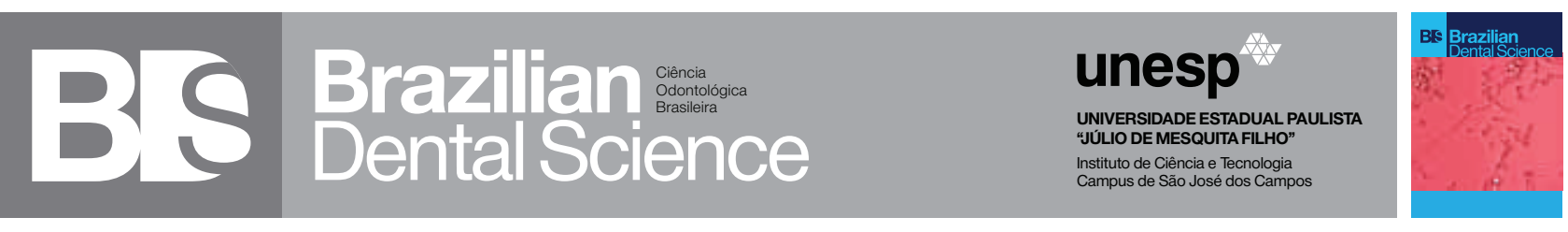

\title{
The use of bisphosphonates in dental clinic: a review of the last five years
}

O uso de bisfosfonatos na clinica dentária: uma revisão dos últimos cinco anos Ü

\author{
Yamba Carla Lara PEREIRA ${ }^{1}$, Glauce Crivelaro do NASCIMENTO ${ }^{2}$ \\ 1 - School of Dentistry of Ribeirão Preto - University of São Paulo - Ribeirão Preto - SP - Brazil. \\ 2 - School of Philosophy, Science and Literature of Ribeirão Preto - University of São Paulo - Ribeirão Preto - SP - Brazil.
}

\section{ABSTRACT}

The bisphosphonates are synthetic drugs used for treatment of neoplasms and bone, Paget's disease and more reason for excitement in cases of postmenopausal osteoporosis. These drugs present some known side effects, however, a new complication with oral manifestation was recently identified, called Osteonecrosis. When this necrosis of the bone bases is associated to the use of Bisphosphonates, it is named Osteonecrosis by Bisphosphonates. The type of bisphosphonate, route of administration, and duration of treatment with these drugs seem to have direct relation with the incidence of osteonecrosis associated with bisphosphonates. The aim of this work was to present a review of the last five years about the use of bisphosphonates, the available bisphosphonate groups in the Brazilian market emphasizing those used in the treatment of Osteonecrosis, and exploring possible diagnostic aspects of the disease from image Diagnostics. It is concluded the impact of current world life stimulates new research areas focusing on important illnesses, their manifestations, and on searching for better treatment protocols and faster diagnosis protocols, aiming reduce possible treatment unwanted side effects.

\section{KEYWORDS}

Biphosphonates; Bisphosphonate associated Osteonecrosis of the jaw; Radiography, dental

\section{RESUMO}

Os bisfosfonatos são drogas sintéticas usadas no tratamento de neoplasias de osso, doença de Paget e nos casos de osteoporose pós-menopáusica. Estas drogas apresentam alguns efeitos colaterais conhecidos, no entanto, uma nova complicação com manifestação oral foi recentemente identificada, chamada osteonecrose. Quando a necrose das bases ósseas está associada à utilização de bisfosfonatos, é nomeada osteonecrose por bisfosfonatos. O tipo de Bisfosfonato, a via de administração e duração do tratamento com estes medicamentos parecem ter uma relação direta com a incidência da osteonecrose. O objetivo deste trabalho foi apresentar uma revisão dos últimos cinco anos sobre o uso de Bisfosfonatos e os grupos de Bifosfonatos disponíveis no mercado brasileiro, enfatizando aqueles usados no tratamento da osteonecrose, além de explorar possíveis aspectos de diagnóstico da doença por meio de imagem. Conclui-se que novas áreas de pesquisa, com foco em doenças importantes e as suas manifestações, estão buscando melhores protocolos no tratamento e diagnóstico rápido, visando reduzir possíveis efeitos colaterais indesejados.

\section{PALAVRAS-CHAVE}

Bifosfonatos; Osteonecrose da arcada osseodentária associada a bisfosfonatos; Radiografias dentárias.

\section{INTRODUCTION}

$\nabla$ he first synthesis of bisphosphonates 1 occurred in the mid-nineteenth century, in 1865 in Germany, for application in industry. However, in humans, the use started about 40 years ago [1]. Bisphosphonates are drugs used in the treatment of metastatic bone disease, Paget's disease, osteoporosis / osteopenia [2]. These drugs have varying potencies and dosages, directly proportional to the risk of bone disorders such as osteonecrosis. Bisphosphonates have been used with good results in children and little or no effects in several diseases: Osteogenesis 
imperfecta, corticosteroid-induced osteoporosis and idiopathic juvenile disuse, metabolic bone disease, heterotopic calcification in soft tissues resistant hypercalcemia, hypervitaminosis $\mathrm{D}$ and fibrous dysplasia (FD) syndrome McCune Albright (SMA) [3]. Bisphosphonates are synthetic analogs of pyrophosphate that inhibit stable growth and dissolution of hydroxyapatite crystals of bone from the reduction of osteoclastic activity [4]. The parenteral administration seems to be associated with a significant number of cases of osteonecrosis of the jaw, whereas only a small percentage of cases were attributed to the use of these drugs orally [5]. Osteonecrosis of the jaw is a pathological change that can result from a complex interaction between bone metabolism, local trauma, infection, and hypovascularization [6]. Systemic factors such as diabetes mellitus, immunosuppression, concomitant use of other medications, such as chemotherapy agents, radiotherapy and corticosteroids, or complication, orthognathic surgery, hematological disorder, especially in patients with sickle cell disease may also develop framework of avascular necrosis of the jaw [7].

In the early stages of the disease, the patients have no specific symptoms, so it is necessary to stay alert to signs like constant pain and throbbing exacerbated by movement of the joint, headache, earache, pain and spasm of the jaw muscles, limitation of mouth opening, crepitus [8]. Osteonecrosis is often progressive and can create extensive areas of exposed bone and dehiscence. When tissues are severely affected, patients may complain of pain and lack of sensitivity [9].

In conventional radiographs structural changes are not observed, but it is possible to see morphological alterations. The magnetic resonance imaging or computed tomography may detect this type of pathology, even in early lesions [10]. The imaging findings can provide important information about the course, magnitude and progression of the disease. The literature states that the radiographic image of the traditional BRONJ is a mixed lesion with areas of bone sclerosis, radiopaque and radiolucent areas of destruction around the teeth and the alveolar crest. Diffuse or regional osteosclerosis, thickened dental lamina dura subperiosteal bone deposition, low density of cancellous bone and bone healing following surgical procedures might also be associated with the condition [11].

The preventive intervention of patients taking bisphosphonate is a good option for management of these cases. Preventive action of health professionals who have access to routine radiographic examination can diagnose sub clinical stages of the osteonecrosis and establish a curative therapy, intercepting the course of the disease before it compromises the patient's life.

The purpose of this literature review was to explore the literature on the use of bisphosphonate. With a bibliographical survey of the literature reviews on the topic in the last five years we intended to present the theme, spread its seriousness as well as alerting the clinician to early manifestations of the osteonecrosis disease, preventing the worsening the clinical scenario.

\section{MATERIAL AND METHODS}

A search was made in PUBMED database [http://www.ncbi.nlm.nih.gov/pubmed] in order to raise all literature reviews and case reports using the keywords "bisphosphonates" and "osteonecrosis", and filter option being the last five years and humans.

\section{LITERATURE REVIEW}

\section{Bisphosphonate drugs}

Bisphosphonates (BPs) are synthetic drugs, analogues of pyrophosphate, in which the oxygen atom has been replaced by a carbon atom in the bisphosphonate molecule. These 
compounds have been synthesized, and used in industry since the 19th century but it is only in the 1960s that their in vitro ability to inhibit the precipitation of calcium phosphate was applied clinically [12].

In this way, in the 60s, BPs have emerged as therapeutic tool in diseases with high bone resorption - neoplastic hypercalcemia, Paget's disease, bone metastases, multiple myeloma, primary and secondary hyperparathyroidism and Osteogenesis imperfecta [13]. Currently, these drugs are the first choice in the treatment of osteoporosis, since it is inexpensive and capable of reducing osteoporotic fractures by $60 \%$ [14] and more than two million people worldwide are treated with BPs [15]. This class of drugs has a significant effect on bone turnover, reducing osteoclastic activity and improving bone mineral density, what result in a reduced risk of osteoporotic fractures.

The BPs can be divided into two groups, nitrogen-containing and non-nitrogencontaining bisphosphonates, differing in the mechanism of action on osteoclasts [16]. Nonnitrogen-containing BPs are taken up by the osteoclasts and trigger intracellular mechanisms leading to apoptosis [17]. These kind of BPs such as etidronate [Didronel], clodronate [Bonefos, Loron], tiludronate [Skelid], are metabolized in the cell that replace the terminal portion ATP pyrophosphate, forming a nonfunctional molecule which competes with adenosine triphosphate (ATP) in cellular energy metabolism. The osteoclast initiates apoptosis and dies, leading to an overall decrease in the breaking of the bone [18].

In contrast, nitrogen-containing BPs, such as pamidronate (APD, Aredia), Neridronate, Olpadronate, Alendronate (Fosamax), Ibandronate (Boniva), Risedronate (Actonel) and Zoledronate (Zometa, Aclasta), act on bone metabolism, binding and blocking the enzyme farnesyl diphosphate synthase (FPP) in inhibitor of HMG-CoA reductase [also known as the mevalonate pathway] [19]. Nitrogen-containing BPs have a complex pathway of action resulting in interference with the osteoclastogenesis, in apoptosis and changes in cytoskeletal dynamics [16]. They are not metabolized, where $50 \%$ are secreted in the urine unchanged, and the rest bind to bone and are slowly released into the circulation; therefore, their half-life in the bone could be as long as 10 years [20].

BPs have also the characteristic of specificity, in that the drugs in question come from two phosphonate groups and, possibly, a hydroxyl in R1, which works together to coordinate calcium ions. The molecules of this medicament have a preference for calcium and bind to it. The largest store of calcium in the human body is in the bones, so BPs tend to accumulate in high concentrations only in bones [18].

\section{Biphosphonated - related osteonecrosis of the jaw (BRONJ)}

Although BPs are the first choice for treatment of osteoporosis, they influence negatively in the clinic therapeutic that require consistency of bone metabolism. They can cause necrotic diseases in bones. The BPs-related osteonecrosis is a clinical entity relatively current. This secondary severely condition affects the quality of life, producing significant morbidity in affected patients [21].

Osteonecrosis is a clinical condition characterized by necrosis of the bone, resulting in systemic factors and sites that compromise the bone vascularity. BRONJ is a pathological change that can result from a complex interaction between bone metabolism, local trauma, infection, hypovascularization and bisphosphonate use. This pathology is a rare but serious complication that can be difficult to manage and may result in significant morbidity to the patient, including severe pain and loss of large portions of the mandible and/or maxilla [22].

Marx [23] first described the association between use of BPs and jaw osteonecrosis. Today, this relationship is well established and is defined as the presence of exposed bone for 8 weeks in patients undergoing treatment with 
bisphosphonates and no history of radiotherapy [24]. Several factors have been implicated in the development of BRONJ, such as high doses of this drug for long periods, advanced age and invasive surgical procedures. The initiation of osteonecrosis can be understood as elicited via inhibition of bone remodeling. BPs incorporate local high bone turnover. The mucosa and periosteum are easily affected by infection or local trauma and the presence of any microtrauma, infection or iatrogenic damage can increase the demand for bone repair thus, exceeding the limits of the capacity of newly formed bones, resulting in osteonecrosis site [25]. Some authors believe also that osteonecrosis injuries are always associated with damage to the gum. This was attributed to the mechanism of apoptosis induced by BPs on osteoclasts and keratinocytes. There is a hypothesis which proposes that apoptosis of these cells result in a reduction and destruction of keratin barrier of the oral mucosa and this consists a pathway that leads to osteonecrosis of the jaws [26].

The American Association of Oral and Maxillofacial Surgeons (AAOMS) established in 2009 that should be considered cases of BRONJ those who submit all of the following [27]:

1 - current or previous treatment with bisphosphonates;

2 - necrotic bone in the jaw region that persists for more than eight weeks and

3 - no history of radiation therapy in maxillomandibular complex

The use of intravenous BPs, especially for a long period, and dentoalveolar surgical procedures are major risk factors for BRONJ. These data are described in a recent systematic review, where the prevalence observed from a sample of 39,124 patients was equal to $6.1 \%$ [28]. Local factors involved are the dentoalveolar surgeries such as tooth extractions, implants, periodontal surgery or periapical. The bisphosphonate-related osteonecrosis is more common in the mandible in patients with previous dental problems [gum disease and tooth abscess] and in regions where the mucosa overlying the bone is thinner [29]. The time between the dental procedure and the development of osteonecrosis ranged between one month and one year [30].

\section{The participation of dental radiographs}

Clinically, BRONJ is similar to osteoradionecrosis and manifests itself as dehiscence and destruction of the oral mucosa with exposure of a necrotic jaw bone, yellow and irregular. This bone necrosis, painless or painful, can arise spontaneously or after dentoalveolar surgery. This pathology can be associated with gingival redness, edema, oozing intra and extra-oral, mobility adjacent teeth, sinusitis, purulent nasal discharge, paresthesia, enlarged lymph nodes, pathological fracture and spontaneous detachment of necrotic bone in the oral cavity [31].

Before the clinical manifestation of necrotic bone exposure, patients may develop an BRONJ with nonspecific symptoms, and may remain so for weeks or months, and at this early stage, little or no radiographic change can be observed and radiographic alterations of BRONJ are not specific [10]. There are characteristic clinical parameters in the diagnosis of BRONJ, but the imaging findings provide important information about the course, magnitude and progression of the disease.

An increase of radiopacity is observed before clinical evidence of the necrosis, mainly in areas of high bone remodeling. The radiologic findings of the BRONJ are found in other conditions such as osteomyelitis, osteoradionecrosis, cancer metastasis, periapical inflammatory lesions [10]. The early phase of BRONJ may not show any significant changes on panoramic and periapical films. In this stage, the imaging findings seem to be sclerosis with poor corticomedullary differentiation and involvement of the inferior alveolar canal which is clinically accompanied by tooth mobility [26]. It is possible to see in BRONJ's images also 
widened periodontal ligament space, unhealed extraction space, osteoclerotic lamina dura and narrowing of the marrow space [27]. Bone sequestrum, fractures, cortical destruction, permeative appearance, areas of low attenuation and periosteal reaction are associated with the late disease. An important finding radiograph of BRONJ is persistent alveolar sockets. In this advanced phase can also be observed areas of mottled bone. In severe cases, the BRONJ creates an ill-defined radiolucency [32].

Radiographs may appear normal when lesions are smaller than $1 \mathrm{~cm}$ and are insensitive in demonstrating the extent of the lesions or complications [33]. The maxilla can be involved with necrosis and in these cases the radiographs may reveal abnormalities in the adjacent maxillary sinus and mucoperiosteal thickening to air-fluid levels [34].

Computed tomography can be useful, because it reveals the full extent of bone involvement and the presence of bone sequestrum. Magnetic resonance [MRI] and bone scintigraphy may also help in the early detection of this disease [35].

\section{Treatment}

There is general consensus in the literature on the fact that dental preventive measures in patients being candidate for or already receiving $\mathrm{BP}$ are extremely important to reduce the risk of BRONJ development. Preventive measures are applied during intravenous bisphosphonate treatment, with endodontic and periodontic therapy preferred over tooth extractions and with avoidance of dental implants [21]. It is important to educate the patient to become cognizant of certain things for example: maintenance of good oral hygiene, routine oral examination, removal of nonviable teeth, completion of any invasive dental treatment and achievement of optimal dental health [26].

The first aim of treating patients with BRONJ is to eliminate clinical symptoms such as pain, treat any infection of the soft tissues or bone, and minimize the progression of bone necrosis [10]. The use of antimicrobial mouth rinses [chlorhexidin or hydrogen peroxide] and/ or analgesia is proposed for patients with clinical evidence of BRONJ such as exposed bone but in the absence of any evidence of infection. They are used to reduce the risk of bone infection (AAOMS, Stage 1) [10]. In the second and third stage where symptoms and signs of infection are present, systemic antibiotics and analgesics are indicated in addition to antimicrobial mouth rinses [36]. Various antibiotic regimens have been tested in several studies such as penicillin, doxycycline, quinolones, metronidazole and clindamycin. Broad-spectrum antimicrobial therapy [phenoxymethylpenicillin, amoxicillin, clindamycin or metronidazol) is recommended although the correct duration of treatment is not clear [36].

The surgical treatment is necessary to remove necrotic bone and create soft tissue coverage of remaining healthy bone. The most commonly recommended approach is to remove symptomatic bony sequestra with minimal soft tissue disturbance and avoiding further bone exposure, although some authors prefer more extensive soft and hard tissue debridement and primary closure of the wound $[28,36]$. More radical surgical management is advocated where there are large segments of necrotic bone or where there is pathological fracture of the bone (AAOMS, stage 3) [36].

Adjunctive therapies suggested for the management of BRONJ include hyperbaric oxygen [HBO], parathyroid hormone, platelet rich plasma and lasers [37]. With the exception of $\mathrm{HBO}$, the literature consists primarily of small case series and further studies need to be undertaken before any are considered for routine use [36].

\section{DISCUSSION}

The importance of the topic Bisphosphonates for health professionals is quite clear. It is essential to understand the risks that dental procedures 
performed in patients who use bisphosphonates, and the impact of possible consequences on the quality of life of patients.

Since 2003, bisphosphonate therapy has been a source of concern in the field of dentistry. This was based on the reports of the first known cases of BRONJ associated with BP intravenous therapy administration. Most situations reported are typically associated with a surgical procedure, a simple extraction, which precipitates the onset of osteonecrosis. The number of dental appointments made by patients treated with BP may increase to facilitate prevention, diagnosis or needed treatment to osteonecrosis [38]. Most cases of BRONJ occur mainly in the posterior region of the mandible, Maxilla may also be affected at the posterior region. The simultaneous involvement of both the maxillary and mandibular bones may also occur [39]. The half-life of BFs is approximately 10 years and the long-term use result in substantial drug accumulation in the skeleton [28]. Thus, it would take a long period of discontinuation of the medication to eliminate the drug from the body. The liquid presentation of the medication is often not possible because of the benefits they provide for the drug treatment for the prevention of osteoporosis and bone metastases [14].

The individual benefit from BP treatment ultimately depends on the weight of risk factors for osteoporotic fracture - such as age, bone mineral density, race, family history and fracture history - and on the presence of risk factors for atypical fractures and other potential complications [40]. These may include treatment duration, pathway of administration and perhaps also the binding properties of the BP in question [40]. Therefore, the optimum duration of treatment is unlikely to be the same in all patients and the benefit of treatment will almost always be greater in patients who are at an elevated risk of osteoporotic fractures. Furthermore, the evidence of bone fracture risk reduction with BPs is somewhat stronger at the short term and the effect of BP treatment does not disappear immediately on pausing the drug or ceasing treatment entirely.
Undoubtedly, the clinical examination is sovereign in diagnosis of osteonecrosis after using BPs, but it is possible, through imaging analysis, to assess the course, magnitude and progression of the disease, allowing clinicians to recognize the risk, consider the action and perform dental procedures safely.

Osteonecrosis leads to physical damage, but also interfere with the quality of life of patients. Thus, it is important for patients who already use BPs or are initiating this treatment, especially by intravenously pathway, to be carefully evaluated by a medical and dental support to avoid the disease.

\section{REFERENCES}

1. Fleisch H. Bisphosphonates: a new class of drugs in diseases of bone and calcium metabolism. Recent Results Cancer Res. 1989;116:1-28.

2. Ferko NC, Borisova N, Airia P, Grima DT, Thompson MF. How rebates, copayments, and administration costs affect the cost-effectiveness of osteoporosis therapies. Manag Care. 2012;21[11]:44-52.

3. Aragão AL, Silva IN. Oral Alendronate Treatment for Severe Polyostotic Fibrous Dysplasia due to McCune-Albright Syndrome in a child: a case report. Int J Pediatr Endocrinol. 2010;2010:432060.

4. Carano A, Teitelbaum SL, Konsek JD, Schlesinger PH, Blair HC. Bisphosphonates directly inhibit the bone resorption activity of isolated avian osteoclasts in vitro. J Clin Invest. 1990;85[2]:456-61.

5. Migliorati CA, Epstein JB, Abt E, Berenson JR. Osteonecrosis of the jaw and bisphosphonates in cancer: a narrative review. Nat Rev Endocrinol. 2011;7[1]:34-42.

6. Arrain Y, Masud T. A current update on osteonecrosis of the jaw and bisphosphonates. Dent Update. 2011;38[10]:672-6.

7. Shannon J, Modelevsky S, Grippo AA. Bisphosphonates and osteonecrosis of the jaw. J Am Geriatr Soc. 2011;59[12]:2350-5.

8. Pazianas M. Osteonecrosis of the jaw and the role of macrophages. J Natl Cancer Inst. 2011;103[3]:232-40.

9. Patel V, McLeod NM, Rogers SN, Brennan PA. Bisphosphonate osteonecrosis of the jaw--a literature review of UK policies versus international policies on bisphosphonates, risk factors and prevention. Br J Oral Maxillofac Surg. 2011;49[4]:251-7.

10. Glueck CJ, Freiberg RA, Boppana S, Wang P. Thrombophilia, hypofibrinolysis, the eNOS T-786C polymorphism, and multifocal osteonecrosis. J Bone Joint Surg Am. 2008;90[10]:2220-9. 
11. Arce K, Assael LA, Weissman JL, Markiewicz MR. Imaging findings in bisphosphonate-related osteonecrosis of jaws. J Oral Maxillofac Surg. 2009;67[5 Suppl]:75-84.

12. McClung M, Harris ST, Miller PD, Bauer DC, Davison KS, Dian L, et al. Bisphosphonate therapy for osteoporosis: benefits, risks, and drug holiday. Am J Med. 2013;126[1]:13-20.

13. Boonyapakorn T, Schirmer I, Reichart PA, Sturm I, Massenkeil G. Bisphosphonate induced osteonecrosis of the jaws: prospective study of 80 patients with multiple myeloma and other malignancies. Oral Oncol. 2008;44[9]:857-69.

14. Reginster J-Y: Antifracture efficacy of currently available therapies for postmenopausal osteoporosis. Drugs. 2011;71:65-78.

15. Dannemann C, Grätz KW, Riener M0, Zwahlen RA. Jaw osteonecrosis related to bisphosphonate therapy: a severe secondary disorder. Bone. 2007;40[4]:828-34.

16. Green J, Clézardin P. The molecular basis of bisphosphonate activity: a preclinical perspective. Semin Oncol. 2010;37[1]:3-11.

17. Lobato JV, Maurício AC, Rodrigues JM, Cavaleiro MV, Cortez PP, Xavier L, et al. Jaw avascular osteonecrosis after treatment of multiple myeloma with zoledronate. J Plast Reconstr Aesthet Surg.2008;61[1]:99-106.

18. Janovská Z. Bisphosphonate-related osteonecrosis of the jaws. A severe side effect of bisphosphonate therapy. Acta Medica (Hradec Kralove). 2012;55[3]:111-5.

19. Nicolatou-Galitis O, Papadopoulou E, Sarri T, Boziari P, Karayianni A, Kyrtsonis MC, et al. Osteonecrosis of the jaw in oncology patients treated with bisphosphonates: prospective experience of a dental oncology referral center. Oral Surg Oral Med Oral Pathol Oral Radiol Endod. 2011;112[2]:195-202.

20. Brados A, Weikel D, Salama A, Goloubeva 0, Schneider A, Rapoport A, et al. . Osteonecrosis of the jaw in multiple myeloma patients: clinical features and risk factors. J Clin Oncol 2006;24:945-52.

21. Lazarovici TS, Yahalom R, Taicher S, Schwartz-Arad D, Peleg 0, Yarom $\mathrm{N}$. Bisphosphonate-related osteonecrosis of the jaw associated with dental implants. J Oral Maxillofac Surg. 2010;68[4]:790-6.

22. Manfredi M, Merigo E, Guidotti R, Meleti M, Vescovi P. Bisphosphonate- related osteonecrosis of the jaws: a case series of 25 patients affected by osteoporosis. Int J Oral Maxillofac Surg. 2011;40[3]:277-84.

23. Marx RE. Pamidronate [Aredia] and zoledronate [Zometa] induced avascular necrosis of the jaws: a growing epidemic. J Oral Maxillofac Surg. 2003;61:1115-7.

24. Abughazaleh $\mathrm{K}$, Kawar N. Osteonecrosis of the jaws: what the physician needs to know: practical considerations. Dis Mon. 2011;57[4]:231-41.
25. Haworth AE, Webb J. Skeletal complications of bisphosphonate use: what the radiologist should know. Br J Radiol. 2012;85[1018]:133342.

26. Allen MR, Burr DB. The pathogenesis of bisphosphonate-related osteonecrosis of the jaw: so many hypotheses, so few data. J Oral Maxillofac Surg. 2009;67[5 Suppl]:61-70.

27. Ruggiero SL, Dodson TB, Assael LA, Landesberg R, Marx RE, Mehrotra B. American Association of Oral and Maxillofacial Surgeons position paper on bisphosphonate-related osteonecrosis of the jaw - 2009 update. Aust Endod J. 2009;35[3]:119-30.

28. Migliorati CA, Siegel MA, Elting LS. Bisphosphonate-associated osteonecrosis: a long-term complication of bisphosphonate treatment. Lancet Oncol. 2006;7[6]:508-14.

29. Hoff AO, Toth B, Hu M, Hortobagyi GN, Gagel RF. Epidemiology and risk factors for osteonecrosis of the jaw in cancer patients. Ann N Y Acad Sci. 2011;1218:47-54.

30. Ganguly R, Ramesh A. Screening for osteoporosis with panoramic radiographs. J Mass Dent Soc. 2012;61[1]:44-5.

31. Filleul 0, Crompot E, Saussez S. Bisphosphonate-induced osteonecrosis of the jaw: a review of 2,400 patient cases. J Cancer Res Clin Oncol. 2010;136[8]:1117-24.

32. Saldanha S, Shenoy VK, Eachampati P, Uppal N. Dental implications of bisphophonate-related osteonecrosis. Gerodontology. 2012;29[3]:177-87.

33. Estilo CL, Van Poznak CH, Wiliams T, Bohle GC, Lwin PT, Zhou Q, et al. Osteonecrosis of the maxilla and mandible in patients with advanced cancer treated with bisphosphonate therapy. Oncologist 2008;13[8]:911-920.

34. Raje N, Woo SB, Hande K, Yap JT, Richardson PG, Vallet S, et al.Clinical, radiographic, and biochemical characterization of multiple myeloma patients with osteonecrosis of the jaw. Clin Cancer Res. 2008;14[8]:2387-2395.

35. Bisdas S, Chambron Pinho N, Smolarz A, Sader R, Vogl TJ, et al. Biphosphonate-induced osteonecrosis of the jaws: CT and MRI spectrum of findings in 32 patients. Clin Radiol. 2008;63[1]:71-7.

36. Bocanegra Perez S, Vincente Barrero M, Sosa Hernandez M, Knezevic M, Castallano Navarro JM, Rodríguez Millares J. Bisphosphonateassociated osteonecrosis of the jaw. A proposal for conservative treatment. Med Oral Patol Oral Cir Bucal. 2008;13[12]:E770-3.

37. McLeod NM, Brennan PA, Ruggiero SL. Bisphosphonate osteonecrosis of the jaw: a historical and contemporary review. Surgeon. 2012;10[1]:36-42.

38. Brozoski MA, Traina AA, Deboni MC, Marques MM, Naclério-Homem MaG. Bisphosphonate-related osteonecrosis of the jaw. Rev Bras Reumatol. 2012;52[2]:265-70. 
39. Martins MA, Martins MD, Lascala CA, Curi MM, Migliorati CA, Tenis $\mathrm{CA}$, et al. Association of laser phototherapy with PRP improves healing of bisphosphonate-related osteonecrosis of the jaws in cancer patients: a preliminary study. Oral Oncol. 2012;48[1]:79-84.
40. Hermann AP, Abrahamsen B. The bisphosphonates: risks and benefits of long term use. Curr Opin Pharmacol. 2013;S14714892[13]00017-9.

\section{Yamba Carla Lara Pereira}

(Correspondig author)

Avenida Bandeirantes, 3900

Monte Alegre - Ribeirão Preto - SP

CEP: $14.040-900$

Received: 2013 Jun 03

e-mail: yambacarla@bol.com.br 